\title{
Lean Implementation Framework for Small and Medium Enterprises Based on Sciencedirect Database: A Systematic Literature Review
}

\author{
Yuli Agusti Rochman ${ }^{1,2}$, Muhammad Kusumawan Herliansyah², Andi Sudiarso ${ }^{2}$
}

IIndustrial Engineering Department, Universitas Islam Indonesia, Indonesia

2Industrial Engineering Department, Faculty of Engineering, Gajah Mada University, Indonesia

${ }^{*}$ Corresponding author. Email: gusti@uii.ac.id

\begin{abstract}
A literature review is one way to gain academic insight based on previous research literature. The academic insight that can be obtained is the newness or originality of the research. The paper-based on the literature also presents the process based on the framework followed. Various fields of research have used literature as a method for conducting previous studies. Some of them are in the fields of technology, health, and society. This research emphasizes the study of lean, manufacturing, and small and medium enterprises (SMEs). Systematic Literature Review (SLR) is one method that provides a framework for conducting literature. ScienceDirect is a digital database that commissions, curates, and displays research. This database was selected in this study because it met the complete inclusion and exclusion criteria. A database accessed through web pages is used to track studies related to the research field to be reviewed. The fit between the criteria provided by the database and the SLR framework helps researchers to obtain research. However, no previous research has developed between the database facility and the SLR framework. This study aims to find this out.
\end{abstract}

Keywords: SLR, SMEs, Lean Implementation Framework

\section{INTRODUCTION}

Industrial globalization has provided opportunities for small and medium enterprises (SMEs) to develop and expand through cost-effectiveness and quality improvement. This encourages SMEs to adopt a modern management system. Lean has been widely considered, accepted, and implemented to improve organizational performance in three dimensions, namely efficiency, profitability, and flexibility.

The application of lean in an organization provides an increase in the company's performance and competitiveness [1,2]. Various lean frameworks have been introduced as a guide in implementing lean. However, the implementation is not easy to do. Lean implementation failure has a big impact on company resources. [3]

Alkhoraif [3] stated that most of the literature on lean implementation is aimed at large industries and there are opportunities for research on SMEs. Initial research was conducted by conducting a literature review to obtain research gaps based on previous literature [4]. The literature review is carried out to determine the position of the research and find the newness or originality of the research to be carried out. Several methods have been introduced to conduct a literature study. These methods include literature review by recording and systematic literature review (SLR).

This study begins by conducting a literature review. The review is based on a collection provided by the ScienceDirect database. The research objectives to identify gaps and provide a better understanding of the lean implementation framework in SMEs are presented in the following series of research questions:

Q1: How to use the ScienceDirect database to do SLR?

Q2: How to apply SLR to a case study of a lean implementation framework in SMEs?

Q3: What is the lean implementation framework in SMEs that has been proposed in previous studies? 


\section{METHODS}

This study aimed to complete a literature review on the lean implementation framework in SMEs, based on the research questions. The systematic review methodology used is the SLR methodology proposed by Tranfield et al. [5].

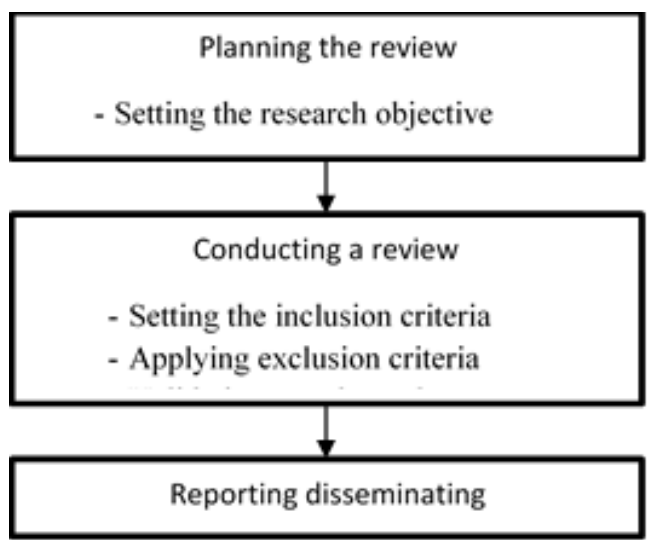

Figure 1. Stages of SLR.

The steps of the SLR method are divided into three, namely planning the review, conducting a review, and reporting disseminating [6].
The first step is divided into two activities, namely setting the research objectives and defining the conceptual boundaries. The second step is divided into three activities, namely setting the inclusion criteria (e.g. search boundary, search term, cover period), applying exclusion criteria, and validating search results. The last stage is reporting disseminating.

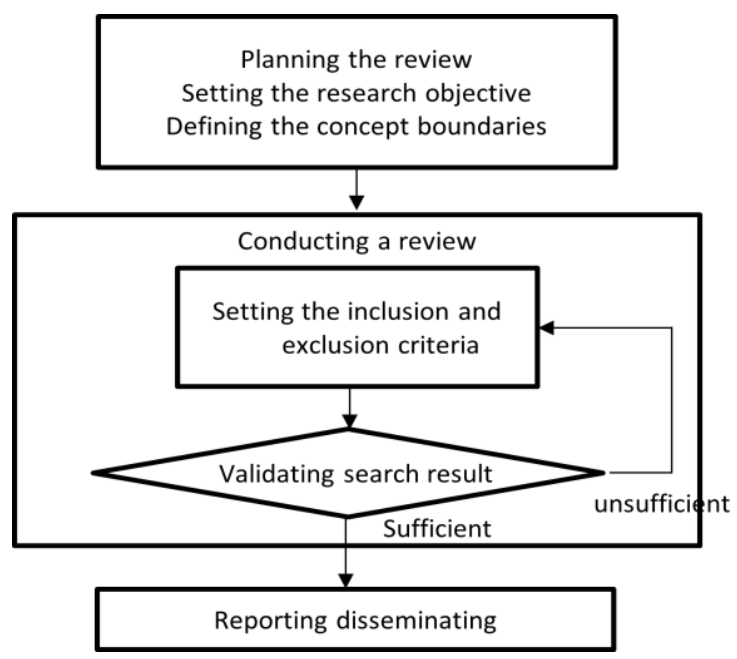

Figure 2. Stages of the proposed SLR literature review.

Table 1. Comparison of search and advanced search fields.

\begin{tabular}{|c|c|c|c|}
\hline Field & Search & $\begin{array}{l}\text { Advanced } \\
\text { Search }\end{array}$ & Explanation \\
\hline Keyword/ terms & $\sqrt{ }$ & $\sqrt{ }$ & $\begin{array}{l}\text { Search all parts of the document for instances of } \\
\text { the term (excluding references). }\end{array}$ \\
\hline Journal/ book title & $\sqrt{ }$ & $\sqrt{ }$ & $\begin{array}{l}\text { Search for documents that contain the terms in } \\
\text { the journal or book title. }\end{array}$ \\
\hline Years & - & $\sqrt{ }$ & $\begin{array}{l}\text { Search for documents of the entered year or } \\
\text { year range. All years must be four digits. }\end{array}$ \\
\hline Author(s) & $\sqrt{ }$ & $\sqrt{ }$ & $\begin{array}{l}\text { Search only the author segments of the docu- } \\
\text { ment for the author name(s). }\end{array}$ \\
\hline Author affiliation & - & $\sqrt{ }$ & $\begin{array}{l}\text { Search the author affiliation segment of the doc- } \\
\text { ument for instances of the terms. }\end{array}$ \\
\hline Volume(s) & $\sqrt{ }$ & $\sqrt{ }$ & \multirow{3}{*}{$\begin{array}{l}\text { In the Volume and Issue field, enter numeric } \\
\text { values only. Use a hyphen to search for a range, } \\
\text { like 1-35. You can use the Page(s) field to } \\
\text { search for article numbers as well. When using } \\
\text { page numbers, only use the first or last page } \\
\text { number, or define the whole range. }\end{array}$} \\
\hline Issue(s) & $\sqrt{ }$ & $\sqrt{ }$ & \\
\hline Page(s) & $\sqrt{ }$ & $\sqrt{ }$ & \\
\hline $\begin{array}{l}\text { Title, abstract, or author-speci- } \\
\text { fied keywords }\end{array}$ & - & $\sqrt{ }$ & $\begin{array}{l}\text { Search only these segments of the document for } \\
\text { instances of the terms. }\end{array}$ \\
\hline Title & - & $\sqrt{ }$ & $\begin{array}{l}\text { Search for documents that contain the terms in } \\
\text { the document title. }\end{array}$ \\
\hline References & - & $\sqrt{ }$ & $\begin{array}{l}\text { Search the bibliographic references cited at the } \\
\text { end of the document. }\end{array}$ \\
\hline ISBN or ISSN & - & $\sqrt{ }$ & Search only these segments of the document. \\
\hline
\end{tabular}




\section{RESULTS AND DISCUSSION}

\subsection{Sciencedirect Database}

ScienceDirect is a full-text database that provides more than 2,500 peer-reviewed journals and 11,000 books [7]. This database performs a search mechanism and retrieves results from several electronic sources. Natural language is used by ScienceDirect to perform search activities like what Google does ScienceDirect provides a feature to search for peer-reviewed journal articles and book chapters (including open access content).

The search filters provided include keywords, author name, journal/book, volume, issue, and page. ScenceDirect provides advanced search features by adding years, author affiliation, title, abstract, or authorspecified keywords, titles, references, and ISBN or ISSN. The comparison between the two is shown in Table 1.

Natural language searching using Boolean operators. Boolean operators currently supported include AND, OR, NOT, and the hyphen (or minus symbol). Boolean operators must be entered in all uppercase. Parentheses can be used when nesting clauses so the grouping is unambiguous. Quotation marks can be used to specify terms that must appear next to each other.

The search results page, sorted by relevance, contains a list of documents that meet the search criteria. The order of search results can be done by relevance or date. The search results can then be filtered using the categories subscribed journals, years, article type, publication title, subject areas, and access type.

\subsection{Planning the Review}

The Planning the Review stage begins with formulating the research objectives. The research objective in this case study is to find and compare lean implementation frameworks in SMEs. The next activity is to define conceptual boundaries. The conceptual limitation in this case study is how the framework helps SMEs implement lean in their organization.

\subsection{Conducting the Review}

The first activity at the conducting the review stage is setting the inclusion criteria. In this activity, we limit science direct as a source of literature review and the paper category is a journal. The search keywords used in the search process are lean, implementation, framework, and small-medium enterprise.

From this search term obtained 6 papers related to search keywords. In our search activity, we limit the literature publication period from 2011 to 2021.

After we determine the inclusion and exclusion criteria, the search results will be validated to find out whether they are following the research objectives. If unsuitable search results are found, exclusion criteria are added to clean up the search results. We add a "lean" filter to title, abstract, or author-specified keywords to remove search results that are not relevant to lean. An example is a paper entitled "System quality and security certification in seven weeks: A multi-case study in Spanish SMEs".

We can validate based on papers with low relevance. After reviewing the entire search results, it is known that the keyword "implementation" is a keyword that contributes to the level of relevance so that it is added to searches for title, abstract, or author-specified keywords. After it is not possible to filter using inclusion and exclusion criteria, then proceed with validation by reviewing the entire search result.

The main purpose of a systematic literature review in this study is to find literature that is following the research objectives, namely to obtain literature that accommodates the keywords lean, implementation, framework, and SME. Based on the search results, obtained 4 relevant literature and 2 irrelevant literature but resulted from the literature search process. 4 of the 6 relevant literature after a more in-depth study based on the title, abstract, and keywords. The percentage of relevant and irrelevant papers is shown in Figure 4.

Table 2. Inclusion and Exclusion Criteria.

\begin{tabular}{|l|l|}
\hline \multicolumn{1}{|c|}{ Inclusion Criteria } & \multicolumn{1}{c|}{ Exclusion Criteria } \\
\hline Database: ScienceDirect & \multicolumn{1}{|c|}{-} \\
\hline $\begin{array}{l}\text { Keywords: lean AND im- } \\
\text { plementation AND } \\
\text { "framework OR road } \\
\text { map" AND SME }\end{array}$ & \\
\hline Year: 2011-2021 & Year: before 2011 \\
\hline $\begin{array}{l}\text { Article type: Research ar- } \\
\text { ticles }\end{array}$ & $\begin{array}{l}\text { Article type: Review arti- } \\
\text { cles, Encyclopedia, Book } \\
\text { chapters, Conference ab- } \\
\text { stracts, Case reports, } \\
\text { Conference info, Corre- } \\
\text { spondence, Data articles, } \\
\text { Discussion, Editorials, } \\
\text { Mini-reviews, Product re- } \\
\text { views, Short communica- } \\
\text { tions }\end{array}$ \\
\hline $\begin{array}{l}\text { Access date: 20 July } \\
2021\end{array}$ & \multicolumn{1}{c}{ - } \\
\hline $\begin{array}{l}\text { Title, abstract, or author- } \\
\text { specified keywords: lean }\end{array}$ & \\
\hline
\end{tabular}




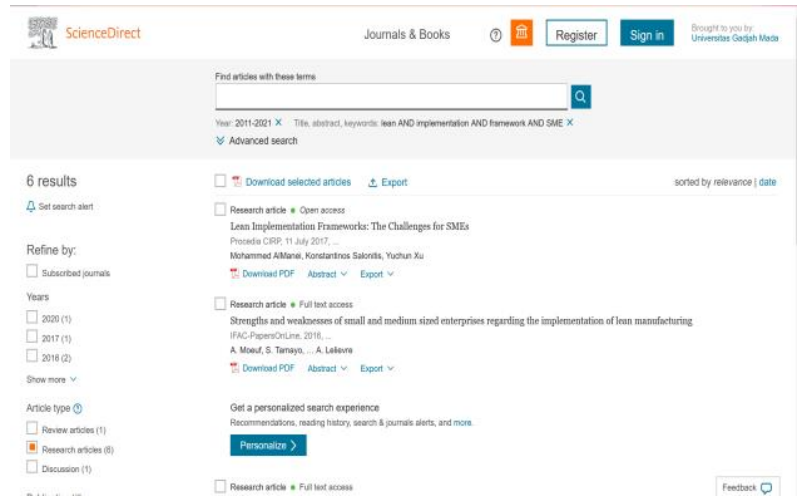

Figure 3. Search results based on keywords after adding "lean" to the title, abstract, or author-specified keywords

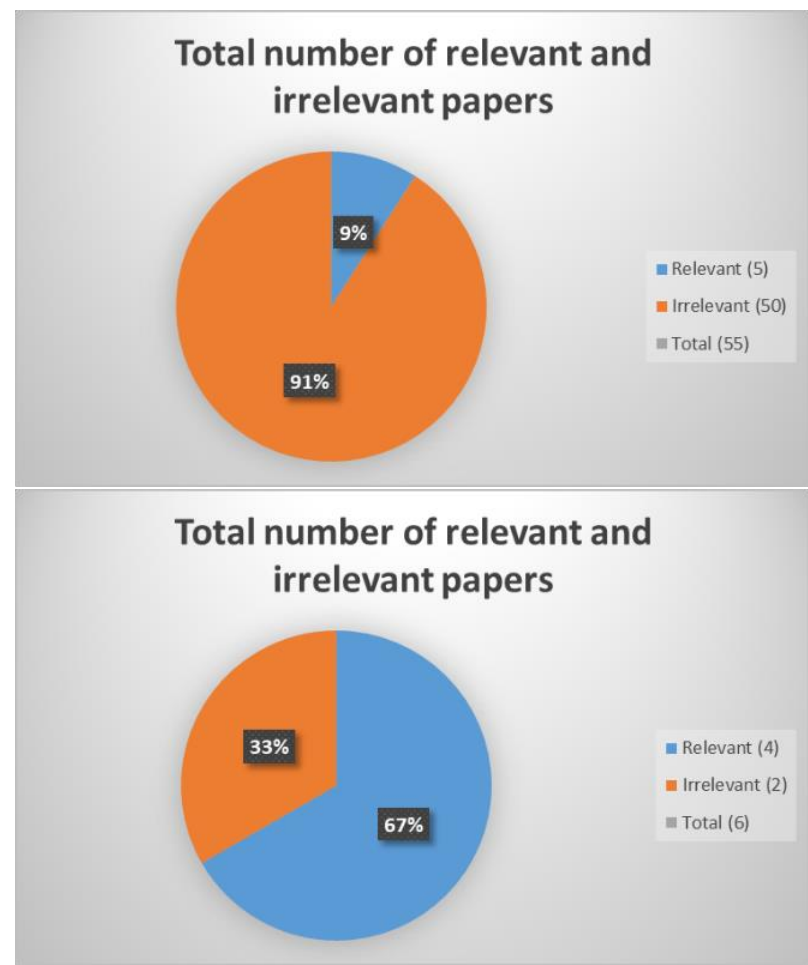

Figure 4. Total number of relevant and irrelevant papers.

Relevant papers include the paper written by Almanei et al. [1], Thanki et al. [2], Afonso \& Cabrita [8], and Nunes [9]. Irrelevant papers were written by, among others, Moeuf et al. [10] and Paul-Eric et al. [11].

The analysis of the results of the literature review focuses on the lean implementation framework in SMEs. Almanei et al. [1] stated that although several lean frameworks have been proposed, many companies find it difficult to implement them. In addition, most lean frameworks are aimed at large manufacturing companies. Therefore, he assesses the lean implementation framework from the SMEs perspective and suggests a dynamic model for a lean roadmap to account for the volatile conditions and the high variability of the environment. Several lean implementation frameworks include 1. 10-step approach focusing on the development of effective working systems and standardization of work, 2. 10-step model, focusing however in design and layout planning, 3. two-phase lean implementation model focusing on social, cultural, and educational aspects, 4. lean implementation framework: Preparation, design and Implementation, and 5. a dynamic model for a lean roadmap to account for the volatile conditions and the high variability of the environment. Thanki et al. [2] develop an integrated framework for a lean-green system to guide SMEs towards sustainable growth.

\section{CONCLUSION}

The conclusions in this study are:

1. The use of the ScienceDirect database is sufficient to fulfill all stages in SLR

2. An additional step in the SLR stage is validating search results.

3. Several lean implementation frameworks in SMEs focus on developing work systems, standardization of work, design planning, layout, socio-cultural, education, preparation, design, implementation, dynamic models, and integrated frameworks.

\section{ACKNOWLEDGMENT}

This study was funded by RTA 2021 grant number 3190/UN1/DITLIT/DIT-LIT/PT/2021 from Gadjah Mada University, Indonesia.

\section{REFERENCES}

[1] Almanei M, Salonitis K and Xu Y 2017 Lean Implementation Frameworks: The Challenges for SMEs Procedia CIRP 63 750-5

[2] Thanki S, Govindan K and Thakkar J 2016 An investigation on lean-green implementation practices in Indian SMEs using analytical hierarchy process (AHP) approach J. Clean. Prod. 135 284-98

[3] Alkhoraif A, Rashid H and McLaughlin P 2019 Lean implementation in small and medium enterprises: Literature review Oper. Res. Perspect. 6100089

[4] Cahyo W N 2020 Finding Novelty of Research with Systematic Literature Mapping (SLM) J. Phys. Conf. Ser.

[5] Tranfield D, Denyer D and Smart P 2003 Towards a Methodology for Developing Evidence-Informed Management Knowledge by Means of Systematic Review Br. J. Manag. 14 207-22 
[6] Wilson J, Arshed N, Shaw E and Pret T 2017 Expanding the Domain of Festival Research: A Review and Research Agenda Int. J. Manag. Rev. 19 195213

[7] Harnegie M P 2013 SciVerse science direct J. Med. Libr. Assoc. JMLA 101165

[8] Afonso H and Cabrita M D R 2015 Developing a lean supply chain performance framework in a SME: A perspective based on the balanced scorecard Procedia Eng. 131 270-9

[9] Nunes I L 2015 Integration of Ergonomics and Lean Six Sigma. A Model Proposal Procedia Manuf. 3 890-7

[10] Moeuf A, Tamayo S, Lamouri S, Pellerin R and Lelievre A 2016 Strengths and weaknesses of small and medium sized enterprises regarding the implementation of lean manufacturing IFAC-PapersOnLine 49 71-6

[11] Paul-Eric D, Rafael P, Cristiane S and Joao C J 2020 How to use lean manufacturing for improving a Healthcare logistics performance Procedia Manuf. 51 1657-64 